\title{
Editorial
}

Int Neurourol J 2014;18:104

http://dx.doi.org/10.5213/inj.2014.18.3.104

pISSN 2093-4777 · eISSN 2093-6931

INJ

CrossMark <click for updates

\section{Metabolomics Goes to Work for You}

\section{Khae Hawn Kim}

Associate Editor

Department of Urology, Gachon University Gil Medical Center, Incheon, Korea

E-mail: kimcho99@gilhospital.com

Currently, biomarker research and the efforts for the application of the research not only for cancer diagnosis, but also for the diagnosis of nervous system disorders, immune diseases, and inflammatory diseases, are becoming more active. In particular, as companion diagnostics have stood out as a requirement for personalized treatment, a new trend has developed in which many multinational pharmaceutical companies have applied companion diagnostic testing techniques for the development of new drugs; this has increased their prospects of leading the molecular diagnostics market worldwide [1]. The US Food and Drug Administration has also provided institutional support, such as help with presenting guidelines for companion diagnostic personalized medicines, since July 2011 [2]. When such developments in the medical industry are combined with efforts to develop revolutionary technologies in the field of genomic analysis, the discovery of urinary metabolic biomarkers related to interstitial cystitis (IC), in the field of urology is considered to bear much significance. In order to achieve this, there is a need to take an approach directed at the discovery of individualized biomarkers for genome-based diagnosis and prediction of disease progression and complications by combining IC-related clinical information with genomic analysis data. In particular, an understanding of the precise nature of clinical characteristics of IC that show ethnicity-based differential expression is needed, along with the development of standard clinical treatment guidelines suited for the unique characteristics of Koreans through evidence-based medicine. For the Chinese medical industry, the development of individualized service products enabling genome-based disease prediction and diagnosis, such as the development of an individualized genomic prediction technique, would be possible; and research that can serve as the cornerstones for establishing the basis and clinical research network is being introduced in this issue [3]. This research is highly significant as it provides an opportunity to apply revolutionary molecular diagnostic technology described in these studies to urinary inflammatory diseases; and this will serve as a good opportunity for application of knowledge from the field of urology to future companion diagnostic research.

In an age when data is driving discovery, it can be said that the results of this study can be used effectively for diagnosis, which is the end stage of hypothesis testing in medical research.

\section{REFERENCES}

1. Khoury JD, Catenacci DV. Next-generation companion diagnostics: promises, challenges, and solutions. Arch Pathol Lab Med 2014 Aug 28 [Epub]. http://dx.doi.org/10.5858/arpa.2014-0063-ED.

2. Doble B, Tan M, Harris A, Lorgelly P. Modeling companion diagnostics in economic evaluations of targeted oncology therapies: systematic review and methodological checklist. Expert Rev Mol Diagn 2014 Aug 21 [Epub]. http://dx.doi.org/10.1586/14737159.2014.929499.

3. Fiehn O, Kim J. Metabolomics insights into pathophysiological mechanisms of interstitial cystitis. Int Neurourol J 2014;18:106-14.

This is an Open Access article distributed under the terms of the Creative Commons Attribution Non-Commercial License (http://creativecommons.org/licenses/by-nc/3.0/) which permits unrestricted non-commercial use, distribution, and reproduction in any medium, provided the original work is properly cited. 